\title{
HOW SOCIOLINGUISTIC THEORY CAN INFORM CULTURAL EVOLUTION, AND HOW TO TEST IT
}

\author{
BETSY SNELLER $^{1}$ and GARETH ROBERTS ${ }^{* 1}$ \\ *Corresponding Author: gareth.roberts@ling.upenn.edu \\ ${ }^{1}$ Department of Linguistics, University of Pennsylvania, Philadelphia, PA, USA
}

In cultural evolution, behavioral variants can be governed by neutral forces or selection, in which individuals are biased in some way. An important bias derives from social meaning: People may select variants that index socially desirable traits. Silverstein (2003) and Eckert (2008) distinguished between different orders of indexicality that a cultural variant may be associated with. First-order indices identify a speaker as belonging to a particular group (defined, e.g., by region or class). A shift to second-order indexicality occurs when variants come to index perceived traits of a group, such as toughness. Second-order indices differ from first-order indices along two dimensions: First, they are more alienable, less inherently connected to a particular group of people. Second, traits indexed by second-order variants are not arbitrary; they are socially relevant characteristics set up in opposition to perceived traits of other groups.

This has consequences for cultural evolution. All things being equal, firstorder indices should spread neutrally; second-order indices should be selected for, propagating at a greater rate. We tested this using an artificial language paradigm devised by Roberts (2010), originally to investigate new-dialect formation. Groups of four participants (160 in total) sat in separate cubicles with computers and played a game in which they took on the role of one of two species of alien: the weaker Wiwos or the (explicitly) tougher Burls. The two species were taught different dialects of the same artificial language (which consisted of twelve words with two or three CV syllables; one dialect would have $b$ where the other had $f$ ). The game consisted of a series of rounds in each of which players were paired up, their species made clear to each other. At the start of the round players chatted in the alien language using text-based instant messaging. Then they could choose to trade resources with each other or (in certain conditions) challenge each other to fights. Each player started with 22 points' worth of resources; the goal was to have the most resources at the end of the game. This could be achieved by trading (where anything given was worth double to the receiver) or, in relevant conditions, by challenging one's partner to a fight. The partner could agree to the fight or run away. If a player lost or ran away, they would lose resources and the 
other player would gain some. Running away was less bad than losing a fight, and scaring an opponent more profitable than winning a fight.

We manipulated the alienability and social relevance of a consonantal feature of the Burl dialect in a $2 \times 2$ design. We manipulated alienability by giving Wiwos an explicit stereotype about the Burl dialect. In inalienable conditions they were told "Burls tend to use $b$ instead of $f$ ". In alienable conditions they were told "Tougher aliens tend to use $b$ instead of $f$." We manipulated social relevance by including or not including fighting in the game. See Table 1 for a summary with condition names.

Table 1. Conditions of the experiment

\begin{tabular}{lll}
\hline & "Tougher aliens" & "Burls" \\
\hline Fighting & Second-order & Relevance-only \\
No fighting & Alienability-only & First-order \\
\hline
\end{tabular}

We then measured the rate at which Wiwos used the Burl consonant. We predicted they should do so more in the Second-order condition (where it was associated with an alienable and socially relevant trait, toughness) than in the first-order condition. As can be seen in Figure 1, the Burl consonant was borrowed to a significantly greater extent in the Second-order than the First-order condition. Interestingly, the other two conditions behaved just like the First-order condition. This study thus provides an empirical test of theoretical notions devised in sociolinguistics and has important consequences for our understanding of how social meaning influences the propagation of cultural variants.

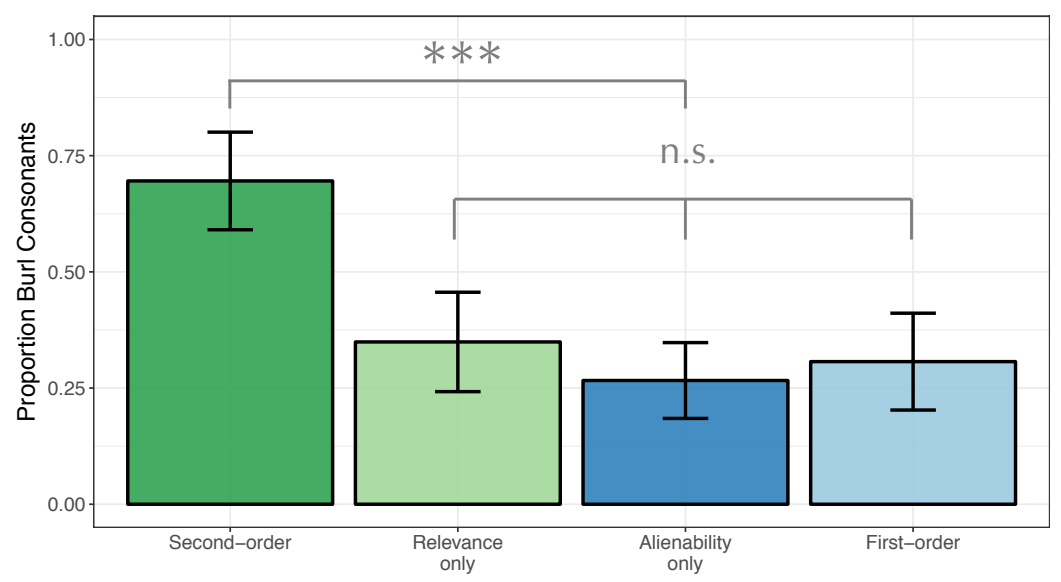

Figure 1. Proportion of Burl consonants used by Wiwos in each condition 


\section{References}

Eckert, P. (2008). Variation and the indexical field. Journal of Sociolinguistics, 12(4), 453-476.

Roberts, G. (2010). An experimental study of the role of social selection and frequency of interaction in linguistic diversity. Interaction Studies, 11(10), $138-159$.

Silverstein, M. (2003). Indexical order and the dialectics of sociolinguistic life. Language and Communication, 23, 193-229. 